\title{
Deficiência intelectual e processos patológicos: historicidade conceitual e os possíveis efeitos nos processos de escolarização
}

\begin{abstract}
Resumo:
O presente estudo tem como objetivo central problematizar e contextualizar a historicidade do conceito de deficiência intelectual, buscando observar e discutir como esta vem sendo compreendida nos últimos anos e quais têm sido os possíveis efeitos em relação aos processos diagnósticos, patológicos e de escolarização. A pesquisa, de cunho qualitativo, utiliza, predominantemente, a pesquisa bibliográfica e a análise documental. A base teórica de referência foi o pensamento sistêmico associado aos estudos do campo da educação especial. A partir da análise, pode-se inferir um tímido debate em relação à perspectiva socioecológica; porém, as formas de avaliação e diagnóstico dos sujeitos com deficiência intelectual seguem uma perspectiva psicométrica. Destaca-se a ação e influência de manuais diagnósticos internacionais no que diz respeito à definição do conceito e dos processos de identificação e diagnóstico no contexto das práticas e da instituição de políticas públicas no contexto brasileiro. A partir do exposto, pode-se concluir que o debate relacionado ao fenômeno da deficiência intelectual, apesar de relevante na produção acadêmica brasileira, apresenta-se complexo e ainda incipiente no que tange ao conceito e aos processos de identificação, avaliação inicial e escolarização desse alunado.
\end{abstract}

\section{Palavras-chave:}

Educação especial. Deficiência intelectual. Inclusão escolar. Patologização. Despatologização da vida.

\section{Intellectual disability and pathological processes: conceptual historicity and the possible effects on schooling processes}

\begin{abstract}
:
The main objective of this study is to problematize and contextualize the historicity of the concept of intellectual disability, seeking to observe and problematize how disability has been understood in recent years and what the possible effects have been as regards the diagnostic, pathological,
\end{abstract}

1 Doutoranda em Educação pelo Programa de Pós-Graduação em Educação da Universidade Federal do Rio Grande do Sul (UFRGS). Professora de Educação Especial no Colégio de Aplicação da UFRGS, Porto Alegre, RS, Brasil. E-mail: carlamacieldasilva@gmail.com. ORCID iD: https://orcid.org/0000-0002-7685-645X. 
and schooling processes. The research, of qualitative nature, predominantly uses bibliographic research and documentary analysis. The theoretical basis of reference was the systemic thinking associated with studies in the field of special education. From the analysis, it is possible to infer a shy debate related to the socio-ecological perspective, however, the forms of assessment and diagnosis of subjects with intellectual disabilities follow a psychometric perspective. The action and influence of international diagnostic manuals stand out, as regards the definition of the concept and the processes of identification and diagnosis in the context of practices and the institution of public policies in the Brazilian context. From the above, it can be inferred that the debate related to the phenomenon of intellectual disability, although relevant in Brazilian academic production, presents itself as a complex and stills incipient discussion, regarding the concept and the processes of identification, initial evaluation, and schooling of the students.

\section{Keywords:}

Special education. Intellectual disability. School inclusion. Pathologization. Depathologization of life.

\section{Discapacidad intelectual y procesos patológicos: historicidade conceptual y posibles efectos en los procesos de escolarización}

\section{Resumen:}

El presente estúdio tiene como objetivo principal problematizar y contextualizar la historicidade del concepto de discapacidad intelectual, buscando observar y problematizar cómo se ha entendido em los últimos anõs y caules han sido los posibles efectos em relación al processos de patológico y de la escolarización. La investigación, de carácter cualitativo, utiliza predominantemente la investigación bibliográfica y el análisis documental. La base teórica de referencia fue el pensamento sistémico associado a los estúdios em el campo de la educación especial. Del análisis es posible inferir um tímido debate em relación a la perspectiva socioecológica, sin embargo, las formas de valoración y diagnóstico de los sujetos com discapacidad intelectual siguen uma perspectiva psicométrica. Se destaca la acción e influencia de los manuales diagnósticos internacionales, en cuanto a la definición del concepto y los processos de indentificación y diagnóstico en el contexto de las prácticas y la institución de políticas públicas en el contexto brasileño. De lo anterior se puede inferir que el debate relacionado con el fenómeno de la discapacidad intelectual, aunque relevante en la producción académica brasileña, se apresenta como uma discusión compleja y aún incipiente, sobre el concepto y los processos de indentificación, evaluación escolar inicial y escolarización.

\section{Palabras clave:}

Educación especial. Discapacidad intelectual. Inclusión escolar. Patologización. Despatologización de la vida.

\section{Introdução}

A deficiência intelectual ${ }^{2}$ ocupou, durante muitos anos, a centralidade das pesquisas acadêmicas na área da educação especial, devido às dificuldades apresentadas nas formas de se definir, conceitualizar e nomear a própria deficiência.

Nessa direção, Stelmachuk e Hayashi (2014, p. 11) problematizam a inexistência de um consenso em relação à natureza da deficiência intelectual e apontam dois modelos que, historicamente, se ocuparam dessa temática: “[...] o modelo médico, de orientação organicista, e o modelo

2 Neste estudo, usaremos o termo "deficiência intelectual", por ser o termo utilizado no contexto brasileiro nos últimos anos. No entanto, é possível que outros termos utilizados historicamente para se referir a esse quadro diagnóstico sejam sinalizados. 
social, baseado na compreensão da incapacidade como um problema social relacionado à funcionalidade, isto é, às estruturas do corpo e à participação social".

Carneiro (2015) discute a deficiência intelectual como uma condição que se desenvolve a partir das relações sociais estabelecidas com sujeitos que apresentam características singulares em relação à maioria da população, e não como uma incapacidade do sujeito.

A heterogeneidade conceitual apresentada ao longo da história envolve diferentes elementos que incidem na complexidade em torno da deficiência em questão. Podemos citar a obscuridade no processo de identificação diagnóstica e, nesse sentido, as fronteiras existentes com os transtornos específicos de aprendizagem; os efeitos dos manuais diagnósticos na vida desses sujeitos; a heterogeneidade conceitual e até mesmo terminológica da deficiência; e o significativo contingente numérico de alunos inseridos nessa categoria no contexto brasileiro. (SILVA, 2016).

No intuito de melhor compreender os caminhos históricos que constituem o conceito dessa deficiência, este texto ${ }^{3}$ propõe-se a problematizar e contextualizar a historicidade do conceito de deficiência intelectual e os processos de patologização ${ }^{4}$ que circunscrevem esses fenômenos.

$\mathrm{Na}$ tentativa de compreender os fenômenos indicados, os procedimentos escolhidos para esta pesquisa de cunho qualitativo são a pesquisa bibliográfica e a análise documental, por serem capazes de auxiliar na construção de um plano analítico que recupere a historicidade e as tensões associadas à escolha de formas destinadas à conceitualização e nomeação. A partir das buscas, os pressupostos do pensamento sistêmico assumiram papel de centralidade no que tange ao plano analítico/metodológico deste estudo.

Dessa forma, faz-se necessário recompor uma história que ganha e produz sentidos, sentidos esses que organizam um conceito e a historicidade de algumas pessoas.

\section{Historicidade do conceito de deficiência intelectual}

No mundo antigo, sendo a cidade de Esparta um exemplo dessas dinâmicas, as crianças com deficiências físicas ou mentais eram consideradas subumanas. Além dos ideais atléticos não alcançados pelos "desviantes da forma", as pessoas religiosas entendiam que a pessoa com deficiência não era merecedora de uma vida padrão, destinada às pessoas reconhecidas como "normais" na época.

Conforme nos indica (SILVA, 2016), é com Paracelso (1493-1542) e Cardano (1501-1576) que a medicina começa, de fato, a problematizar a deficiência, que ainda era encarada com um olhar supersticioso, mas não teológico, em que o "louco" e o "idiota" são doentes ou vítimas de forças subumanas e dignos de tratamento, como a alquimia, a magia e a astrologia.

Em 1534, a patologia da deficiência passa a ser norma de jurisprudência na Inglaterra, limitando os direitos civis das pessoas com deficiência. (PESSOTTI, 2012). Nomeada na época como loucura ou idiotia, essa condição passa a ser definida como enfermidade a partir da jurisprudência.

Inútil para a sociedade: era assim que o sujeito com deficiência intelectual era visto, pois não servia para a lavoura nem para o artesanato. A partir desse período, a saída encontrada foi a do afastamento desses sujeitos para espaços onde eles receberiam teto e comida, sendo a segregação a alternativa prevista naquele momento, evitando o possível incômodo provocado pela presença de um sujeito com deficiência.

Em 1799, no sul da França, um acontecimento marcou a história relativa à educação das pessoas com deficiência. Teria sido encontrado, nas florestas de La Caune, um menino que era considerado selvagem, em função de suas características. Após passar por alguns abrigos, o menino

3 Parte do presente artigo tem sua origem na pesquisa de mestrado desenvolvida por Silva (2016).

4 A patologização ocorre segundo uma concepção de ciência médica que discute o processo saúde-doença como centrado no indivíduo, privilegiando a abordagem biológica, organicista. 
é encarregado ao Instituto Nacional de Surdos-Mudos, na França, e dois médicos passam a ter contato mais direto com o menino-selvagem: Philippe Pinel e Jean Itard.

Philippe Pinel é encarregado de examinar o menino. Porém, a avaliação feita é desanimadora:

Procedendo, inicialmente, pela exposição das funções sensoriais do jovem selvagem, seus olhos sem fixidez, sem expressão, errando vagamente de um objeto ao outro sem jamais deter-se sobre algum, o órgão do ouvido insensível aos mais intensos ruídos, a voz reduzida a um estado de completa mudez [...] desprovido de memória, de julgamento, de capacidade de imitação e tão limitado nas ideias, mesmo que relativas às suas necessidades, que ele não conseguiu ainda nem mesmo abrir uma porta ou subir a uma cadeira para atingir alimentos pendurados acima do alcance de sua mão; finalmente desprovido de qualquer meio de comunicação, não ligando nem expressão nem intenção aos gestos e movimentos de seu corpo [...] toda a sua existência, numa palavra, uma vida puramente animal. (BANKS-LEITE; GALVÃO, 2000, p. 131-132, grifos do autor).

Jean Marc Itard (1774-1838) passa a trabalhar na instituição como médico-residente e, contrariando seus colegas que entendiam o selvagem como um incapaz, defende, com extrema convicção, a possibilidade de educar o menino.

Para além dos escritos de Pinel sobre Victor (nome que lhe é atribuído por Itard), Itard nos auxilia a refletir que, apesar do diagnóstico, da avaliação que chega a nós, professores, devemos compreender por que o sujeito se institui de tal forma, sua história, seu enredo.

Todo o trabalho desenvolvido por Itard com Victor aponta uma questão até hoje bastante polêmica na educação especial: a da avaliação. O diagnóstico dado por Pinel encaminha Victor a uma instituição hospitalar para dementes, sem oportunidade de ensino ou educação. A visão de Itard, porém, considerava a educabilidade do selvagem, ainda que não houvesse uma metodologia para tal. (CARNEIRO, 2007, p. 14-15).

A experiência pedagógica relatada destaca duas visões no que tange à deficiência intelectual na época, uma caracterizada pela predominância nas discussões relacionadas à temática e outra que começava a conquistar espaço: respectivamente, a médico-clínica, que, nessa experiência, é indicada por Pinel, e a médico-pedagógica, apontada no trabalho de Itard com Victor. Pela primeira vez na história, há uma experiência pedagógica sistematizada e financiada, com o intuito de criar mecanismos para a educação desse menino e para documentar um conjunto de práticas.

As descobertas e teorizações de Itard podem ser consideradas como "[...] a fundação da educação especial para as pessoas com deficiência, particularmente aquelas com deficiência mental". (TEZZARI, 2009, p. 82). No entanto, o "olhar pedagógico" nessa época (e, em especial, nesse exemplo) foi instituído pela área médica.

Dessa forma, compreensões associadas à patologização e a estreita associação a aspectos orgânicos e/ou funcionais dos sujeitos faz com que profissionais como Pinel atribuíssem suas pesquisas ao intuito de comprovar graus ou tipos de deficiência e distinguir "cretinos, idiotas, cretinoides, imbecis e retardados".

Nesse sentido, a criação de exames na tentativa de quantificar as capacidades mentais, a inteligência e a memória ganhavam espaço considerável entre as discussões e pesquisas de estudiosos no início do século XX. Era de entendimento, por parte dos pesquisadores da época (Foderé, Séguin, Binet, Esquirol), a existência de níveis de deficiência intelectual.

5 Deficiência mental: nomenclatura utilizada pela autora.

6 Nomenclaturas utilizadas na época. 
As questões que impulsionaram os estudos de Alfred Binet, por exemplo, eram a retenção escolar na escola pública: sua teoria parte da observação de crianças que, segundo ele, "falhavam" na realização escolar. Posterior a esse momento, relaciona a incapacidade intelectual "relativamente leve" ao que irá nomear de "debilidade mental".

$\mathrm{Na}$ tentativa de medir as capacidades mentais, o diagnóstico psicológico e os estudos da contribuição psicométrica se propõem a auxiliar na identificação daqueles que não possuem uma deficiência mental "profunda ou grave". Binet começou a publicar estudos relacionados aos testes psicométricos no final do século XIX e início do século XX. O objetivo era a criação de instrumentos que permitissem identificar as crianças que estariam sujeitas ao fracasso escolar. E é a partir dos estudos de Binet e Simon (1905) que é introduzida a noção de quociente intelectual (QI), propondo uma relação entre a idade cronológica e a idade mental identificada nos testes capazes de medir a inteligência.

Temos, portanto, duas concepções para definir a deficiência intelectual nessa época: a biológica e a psicológica. Relacionada a essas duas concepções, o ponto alto de análise da época era como diagnosticar o débil (deficiente mental leve $e^{7}$ ), aquele que, segundo o pesquisador, não possuía traços físicos da idiotia, que estava frequentando a escola, em convívio com os demais alunos, e que apresentava "desvios da normalidade".

Assim, mais uma vez, a área médica adentra os muros da escola no intuito de classificar e diagnosticar crianças que estavam em processo de aprendizagem. Até a atualidade, a identificação e o processo diagnóstico desses alunos continuam sendo um território nebuloso. É necessária, aqui, a compreensão da configuração dos testes de inteligência criados por Binet, pois os níveis ou graus de deficiência ainda são utilizados sob algumas perspectivas e indicados pelos atuais manuais de classificação diagnóstica. Os testes de inteligência sofrem, hoje em dia, questionamentos quanto ao seu uso. No cenário mundial, alguns movimentos problematizam o uso desses testes, afirmando não ser o único método possível e necessário para a constituição do processo diagnóstico. No entanto, veremos, no decorrer desta escrita, que testes de QI e diferentes tipos de testes padronizados continuam sendo utilizados, reforçando uma lógica patologizante e nada contextual sobre o desenvolvimento de nossas crianças e adolescentes.

$\mathrm{Na}$ ampliação do debate acerca da deficiência intelectual, ainda durante o primeiro período do século XX, sua dimensão teórica e conceitual passa a ser um campo de estudo também da psicologia, deixando de ser propriedade apenas da área médica. As definições biológicas, sociais e educacionais também foram assuntos de grande debate nesse período. Em relação à educação, o ensino especial constitui-se como alternativa de escolarização para esses alunos; dessa forma, as pessoas identificadas com deficiência mental não possuem mais apenas a alternativa de ir para asilos ou hospícios, como ocorrera em momento anterior.

Contudo, como sinalizado anteriormente, o debate acerca da classificação diagnóstica e também da organização de sistemas de apoio começa a ganhar amplitude no cenário mundial, sobretudo nos Estados Unidos, onde, a partir da década de 1950, um grupo de estudiosos passa a problematizar a definição de deficiência intelectual, nomeada, nessa época, em boa parte do contexto mundial, como retardo mental. Trata-se de um grupo que, alguns anos depois, organiza a Associação Americana de Retardo Mental ${ }^{8}$.

Para além da busca em se definir e conceitualizar a deficiência intelectual, por volta das décadas de 1950 e 1960, questionava-se sobre a melhor forma de nomear essa deficiência. Nesse sentido, a Organização das Nações Unidas (ONU) recomendou, em 1954, o termo "retardo mental"

7 Nomenclaturas e conceitos utilizados na época.

8 Nomenclatura utilizada desde sua criação até 2007, ano em que associação modifica sua nomenclatura para Associação Americana de Deficiência Intelectual e Desenvolvimento (AAIDD). 
para aqueles casos relacionados a causas orgânicas e "deficiência mental” para casos relacionados a fatores ambientais.

No manual de 1992, a AAMR objetivou problematizar a necessidade de não se analisar a deficiência como um traço absoluto do sujeito, e sim como fruto de uma interação do funcionamento intelectual e o ambiente. No entanto, nesse período, o teste psicométrico continuava sendo um dos principais balizadores da construção diagnóstica, caminhando na direção contrária a uma compreensão mais contextual e não intrínseca ao sujeito.

Em 2002, a Associação Americana reorganiza seu manual e define: “[...] retardo mental é uma incapacidade caracterizada por limitações significativas no funcionamento intelectual e na conduta adaptativa que se manifestam em habilidades práticas, sociais e conceituais. Esta incapacidade começa antes dos 18 anos." (AAMR, 2002, p. 24).

No referido sistema, são problematizados, com maior ênfase, os processos de diagnóstico e classificação e os níveis de suporte. Ampliam-se as discussões sobre a necessidade de julgamento clínico no processo diagnóstico. Segundo a AAMR (2002), a deficiência em questão somente é diagnosticada se atender a três requisitos: funcionamento intelectual, habilidades adaptativas e idade de "aparição"” do déficit.

Em 2010, a 11 a edição desse manual introduziu uma mudança que alterou a terminologia de retardo mental ${ }^{10}$, utilizada predominantemente até 2010, para deficiência intelectual. Essa mudança tem influenciado a publicação de documentos brasileiros que, por sua vez, vêm se apropriando desse conceito, assim como de suas recomendações para a identificação de pessoas com deficiência intelectual.

A mudança terminológica ocorreu no ano de 2010; porém, a alteração terminológica não está associada necessariamente a uma mudança conceitual, visto que este permanece inalterado desde o $9^{\circ}$ manual de classificação, publicado em 1992.

A deficiência intelectual, segundo o Sistema 2010, define-se da seguinte forma:

[...] incapacidade caracterizada por importantes limitações, tanto no funcionamento intelectual quanto no comportamento adaptativo, está expresso nas habilidades adaptativas conceituais, sociais e práticas. Essa incapacidade tem início dantes dos dezoito anos de idade. (AAIDD, 2010, p. 25, tradução própria).

Ao analisarmos o plano conceitual da definição de deficiência intelectual, podemos apontar que, no Sistema 2010, dá-se, ainda, grande importância ao constructo de funcionamento intelectual e, quando há uma sinalização de operacionalidade, ela é associada à aplicação de testes psicométricos para a identificação do quociente de inteligência.

Assim como o funcionamento intelectual, o comportamento adaptativo no processo diagnóstico é analisado por testes padronizados e necessita de um julgamento clínico ${ }^{11}$. Nesse sentido, o funcionamento intelectual e a conduta adaptativa, segundo a Associação Americana ${ }^{12}$, devem ser avaliados através de parâmetros normatizadores associados a testes que envolvam uma estandardização. Dessa forma, a análise desses dois fatores - o funcionamento intelectual e o comportamento adaptativo - nos mostra que, apesar da ênfase anunciada como possível avaliação multirreferenciada, esses parâmetros mais quantitativos continuam sendo balizadores para a identificação do diagnóstico.

9 Termo utilizado nos sistemas de classificação da AAMR.

10 Anteriormente, grande parte dos países utilizava a designação "retardo mental”, segundo o atlas Global Resources for Persons with Intellectual Disabilities (Recursos Globais para Pessoas com Deficiência Intelectual). (WHO, 2007).

11 Entende-se por "julgamento clínico" o processo de avaliação diagnóstica realizado por profissionais da saúde.

12 Essa afirmação também é válida para o DSM-5. (APA, 2014). 
É possível compreender a existência de um investimento da AAIDD em apontar a perspectiva socioecológica em associação ao constructo de deficiência intelectual, principalmente ao instituir a alteração do termo "retardo mental". A associação esclarece que a mudança terminológica ocorre na tentativa de fazer com que a deficiência deixe de ser compreendida como um traço centrado na pessoa. Essa tentativa alinha-se aos preceitos acordados em 2006 pela Convenção da ONU sobre os Direitos das Pessoas com Deficiência, que apresentou uma definição de deficiência com uma forte conotação social, defendendo o pressuposto de que não seria algo centrado no sujeito, mas sim nas suas interações com o meio social circundante. Porém, o delineamento associado ao processo de identificação nos leva a reconhecer que as alterações são discretas e que permanecem as diretrizes históricas no entendimento desse conceito (ONU, 2006).

Nessa mesma direção, o DSM- $5^{13}$, publicado em 2013 e organizado pela Associação Americana de Psiquiatria (APA), indica a nomenclatura de deficiência intelectual, compactuando com o cenário mundial, e aponta que testes padronizados, como os de QI, não devem determinar o diagnóstico tampouco os níveis de gravidade (os quais são descritos pelo manual), sinalizando que estes devem ter como base o funcionamento adaptativo. No entanto, em nenhum momento o DSM-5 indica de forma clara a exclusão do uso de testes de QI. (APA, 2014).

Portanto, podemos inferir que, ao analisarmos as tentativas de rupturas referentes a uma perspectiva mais patologizante da compreensão da deficiência intelectual e da valorização de uma perspectiva socioecológica, a compreensão acerca da incapacidade e de uma condição intrínseca ao sujeito ainda é muito presente.

No contexto brasileiro, a partir da Convenção da ONU sobre os Direitos das Pessoas com Deficiência e de diversos movimentos políticos, mudanças estruturais são instituídas no que tange à consolidação de uma perspectiva inclusiva. Nesse sentido, crianças consideradas público-alvo da educação especial passam a ter assegurada a garantia do direito ao acesso a escolas regulares a partir da Política Nacional de Educação Especial na Perspectiva Inclusiva, de 2008, que, junto com as demais normativas desenvolvidas desde a sua criação, evidencia um pensamento que está em consonância com a perspectiva social da deficiência e com a compreensão de que os processos de escolarização devem ser mais inclusivos e menos patologizantes. (BRASIL, 2008).

Contudo, dados quantitativos apontam uma crescente no contingente numérico de alunos sendo inseridos na categoria de deficiência intelectual, o que aponta para a necessidade de cautela, devido ao debate aqui explorado a respeito de uma contínua tendência à compreensão da deficiência como intrínseca ao sujeito e associada a uma possível incapacidade.

Dessa forma, ressalta-se a importância de mais investimento em pesquisas e da problematização de procedimentos diagnósticos, assim como da compreensão conceitual de deficiência intelectual, por observarmos os possíveis efeitos desses engendramentos no contexto escolar, na organização das práticas escolares destinadas a esses sujeitos e em uma possível percepção equivocada, que pode mais patologizar e estigmatizar do que incluir.

\section{Considerações finais e os possíveis efeitos no que tange aos processos diagnósticos e de escolarização}

Este estudo teve o objetivo de apresentar a historicidade do conceito de deficiência intelectual, sobretudo no século XX, e seus possíveis efeitos no que tange aos processos patológicos e de escolarização desses sujeitos. Fica perceptível o quanto as visões sociais e teóricas influenciaram em serviços, tratamentos e processos de identificação para aqueles diagnosticados com essa deficiência.

13 Um dos mais influentes manuais diagnósticos, organizado pela Associação Americana de Psiquiatria, o Manual Diagnóstico e Estatístico de Transtornos Mentais (Diagnostic and Statistical Manual of Mental Disorders - DSM), que está em sua quinta versão. 
A mudança terminológica referida, instaurada pela a AAIDD, denota um tímido debate em relação à perspectiva socioecológica, porém, como já problematizado anteriormente, as formas de avaliação diagnóstica dos sujeitos com deficiência intelectual seguem uma perspectiva psicométrica, apontando o funcionamento intelectual e a conduta adaptativa abaixo da média como principais indicadores para um diagnóstico de deficiência intelectual.

Ao analisarmos sua constituição conceitual, compreendemos que, apesar de termos acompanhado alguns avanços quanto à compreensão do conceito de deficiência, ainda é possível identificar o predomínio de uma lógica que tende a valorizar uma dimensão individual e intrínseca ao sujeito nos critérios diagnósticos, atribuindo supostas desvantagens àqueles que são alvo da ação classificadora.

A partir desses engendramentos, no Brasil, temos acompanhado, nos últimos anos, o aumento expressivo do contingente numérico de alunos inseridos na categoria de deficiência intelectual no Censo Escolar MEC/INEP (SILVA, 2016). Ao analisarmos os dados mais recentes disponíveis no site do INEP/MEC ${ }^{14}$, averiguamos que, em 2019, o Brasil possuía um contingente numérico de 1.090.805 alunos matriculados como público-alvo da educação especial em classes comuns de ensino, e, destes, 709.683 foram inseridos na categoria "deficiência intelectual". Ou seja, podemos considerar que cerca de $65 \%$ das matrículas gerais do público-alvo da educação especial são ocupadas por alunos diagnosticados com deficiência intelectual. Esse grande contingente numérico torna-se ponto de análise e cautela, por acompanharmos indícios do aumento da inflação diagnóstica recorrente nas últimas décadas. Temos vivenciado a necessidade de classificar o que foge aos parâmetros estabelecidos pelo campo diagnóstico e pela compreensão de normalidade.

Como sinalizado inicialmente nesta escrita, a conceitualização, a nomeação e os processos diagnósticos que envolvem a deficiência intelectual, formam uma rede complexa cujo principal objetivo é o da classificação. Bezerra Junior (2014, p. 13) nos auxilia ao lembrar que "[...] classificações não são espelhos da realidade, mas construções, arranjos, que configuram uma realidade". Em outras palavras, a classificação diagnóstica, por si só, será sempre arbitrária, ocasionando a impossibilidade de se reproduzir fielmente um contexto.

A complexidade que acompanha os estudos referentes à deficiência intelectual pode ser considerada preconizadora de efeitos no que tange aos processos diagnósticos e de escolarização. No contexto escolar, ao longo da última década, temos acompanhado a intensa relação da deficiência intelectual com as dificuldades de aprendizagem e com o fracasso escolar, como nos apontam Jannuzzi (1992) e Ferreira (1992). Essa proximidade indica a ocorrência de fragilidade nas fronteiras associadas a esses diferentes grupos. Bridi (2011) problematiza algumas características que identificam o sujeito com deficiência mental ${ }^{15}$ no olhar das educadoras entrevistadas em sua pesquisa:

As professoras especializadas, ao caracterizarem a deficiência mental, referem dificuldades de organização do pensamento e na construção de conceitos; limitações no uso desses conceitos em diferentes lugares e situações; dificuldades em acompanhar o mesmo nível de exigência pedagógica da turma. Enfim, as características da deficiência mental aparecem relacionadas a uma dificuldade e/ou um prejuízo nas aprendizagens escolares, que são evidenciados por meio das dissonâncias entre faixa etária e conhecimento suposto pelas manifestações do aluno. Dessa forma, é possível perceber a primazia das habilidades intelectuais e, por decorrência, a valorização da dimensão conceitual e acadêmica na caracterização da deficiência mental. (BRIDI, 2011, p. 180).

14 Os dados foram extraídos do site do INEP/MEC na aba Educação Básica, em sinopses estatísticas da educação básica. Os dados foram acessados através da pasta em Excel disponibilizada contendo todos os dados extraídos da pesquisa realizada para o Censo Escolar MEC/INEP.

15 Nomenclatura utilizada na referência. 
Nesse sentido, Silva e Baptista (2021) apontam a valorização da lógica patologizante da vida nos contextos educacionais e nos fazem refletir que, apesar dos avanços na compreensão social do conceito de deficiência, ainda é possível encontrarmos uma forte tendência de ideias que reforçam a perspectiva de uma suposta "capacidade intelectual".

A ampliação numérica do contingente de alunos identificados com deficiência intelectual, segundo os dados do INEP, e a hipótese de que essa ampliação esteja associada a um contingente de alunos que apresentam dificuldades escolares e de aprendizagem, e não necessariamente a dificuldades relacionadas à deficiência, mostram que devemos problematizar o que significa, de fato, aprender. Pois o que é mesmo "aprender"?

Conforme nos indica Silva (2016), segundo Maturana e Varela (1992, p. 244), "aprender" relaciona-se com nossas interações: “[...] o que é aprender? O aprender é conviver, quer dizer, o aprender se dá de uma maneira ou de outra na transformação que tem lugar na convivência, e consiste em viver o mundo que surge com o outro".

A partir dessa perspectiva, é impossível considerarmos a aprendizagem como uma característica humana estática e intrínseca, pois depende das relações que o sujeito tem em suas experiências com o mundo e com os outros. A vivência escolar é parte desse universo de relações.

Se a criança está em um contexto de relações, se as trocas e as aprendizagens acontecem a partir das interações, questiono-me sobre a valorização de um processo diagnóstico baseado, em modo quase exclusivo, na perspectiva psicométrica, que, na maioria das vezes, é realizado utilizando testes que buscam medir a "capacidade intelectual" do aluno. O Sistema 2010 e o DSM-5 apontam que, no processo de identificação dos alunos com deficiência intelectual, deve-se considerar o contexto em que o sujeito está inserido. Porém, os testes psicométricos avaliam apenas uma dimensão quantificável daquilo que seria a capacidade intelectual do sujeito.

O contínuo investimento em parâmetros quantificadores e os sinais de que há possíveis fragilidades na avaliação inicial e no processo de identificação da deficiência intelectual nos faz refletir sobre a necessidade de buscarmos novas referências para o processo de avaliação.

Assim, compreendemos que o investimento em uma perspectiva despatologizante, como uma nova ótica para a análise dos processos sociais e diagnósticos e para a compreensão conceitual da deficiência intelectual, continua sendo nosso grande desafio. Trata-se de uma busca de construção de parâmetros analíticos que evoquem uma análise que considere o sujeito em seu contexto.

Logo, podemos inferir que a concepção classificadora e valorizadora da patologização não corrobora com uma visão sistêmica, pois encara os fenômenos de forma isolada. Ao assumirmos uma observação contextual e menos simplificadora sobre nossos alunos, tendemos a reconhecer com mais facilidade as relações e interações que se estabelecem durante os processos de escolarização desses estudantes.

A partir do exposto, podemos concluir que o debate acerca do fenômeno da deficiência intelectual, apesar de relevante na produção acadêmica brasileira, apresenta-se complexo e ainda incipiente, no que tange ao conceito, ao processo de avaliação diagnóstica e de escolarização desse alunado. Desse modo, destaca-se que as produções referentes à temática estudada nesta pesquisa continuam sendo necessárias no contexto brasileiro, o que justifica a importância de novos investimentos em pesquisas da área.

\section{Referências}

AMERICAN ASSOCIATION ON INTELLECTUAL AND DEVELOPMENTAL DISABILITIES (AAIDD). Intellectual disability: definition, classification, and systems of supports. 11. ed. Washington: AAIDD, 2010. 
AMERICAN ASSOCIATION ON MENTAL RETARDATION (AAMR). Retardo mental: definição, classificação e sistemas de apoio. 10. ed. Porto Alegre: Artmed, 2006.

AMERICAN PSYCHIATRIC ASSOCIATION (APA). DSM 5 - manual diagnóstico e estatístico de transtornos mentais. 5. ed. rev. Porto Alegre: Artmed, 2014.

BANKS-LEITE, Luci; GALVÃO, Isabel. (org.). Uma introdução à história de Victor do Aveyron e suas repercussões. In: BANKS-LEITE, Luci. A educação de um selvagem: as experiências pedagógicas de Jean Itard. São Paulo: Cortez, 2000. p. 11-24.

BEZERRA JUNIOR, Benilton. A psiquiatria contemporânea e seus desafios. In: ZORZANELLI, Rafaela; BEZERRA JUNIOR, Benilton; COSTA, Jurandir Freire. (org.). A criação de diagnósticos na psiquiatria contemporânea. Rio de Janeiro: Garamond, 2014. p. 9-31.

BRASIL. Ministério da Educação. Secretaria de Educação Especial. Política Nacional de Educação Especial na Perspectiva da Educação Inclusiva. Brasília: MEC/SEESP, 2008.

BRIDI, Fabiane Romano de Souza. Processos de identificação e diagnóstico: os alunos com deficiência mental no contexto do atendimento educacional especializado. 2011. 210 f. Tese (Doutorado em Educação) - Programa de Pós-Graduação em Educação, Faculdade de Educação, Universidade Federal do Rio Grande do Sul, Porto Alegre, 2011.

CARNEIRO, Maria Sylvia Cardoso. Deficiência mental como produção social: uma discussão a partir de histórias de vida de adultos com síndrome de Down. 2007. 195 f. Tese (Doutorado em Educação) - Programa de Pós-Graduação em Educação, Faculdade de Educação, Universidade Federal do Rio Grande do Sul, Porto Alegre, 2007.

CARNEIRO, Maria Sylvia Cardoso. A deficiência intelectual como produção social: reflexões a partir da abordagem histórico-cultural. In: REUNIÃO ANUAL DA ANPED, 37., 2015, Florianópolis. Anais [...]. Florianópolis: ANPED, 2015. Disponível em: https://www.anped.org.br/sites/default/files/trabalho-gt15-4079.pdf. Acesso em: 05 jun. 2021.

FERREIRA, Júlio Romero. Notas sobre a evolução dos serviços de educação especial no Brasil. Revista Brasileira de Educação Especial. Marília, p. 101-107, 1992.

JANNUZZI, Gilberta. A luta pela educação do deficiente mental no Brasil. 2. ed. Campinas: Autores Associados, 1992.

ORGANIZAÇÃO DAS NAÇÕES UNIDAS (ONU). Convenção sobre os Direitos das Pessoas com Deficiência. Nova York: ONU, 2006.

PESSOTTI, Isaías. Deficiência mental: da superstição à ciência. Marília: ABPEE, 2012.

SILVA, Carla Maciel. Deficiência Intelectual no Brasil: uma análise relativa a um conceito e aos processos de escolarização. 2016. 103 f. Dissertação (Mestrado em Educação) - Programa de Pós-Graduação em Educação, Faculdade de Educação, Universidade Federal do Rio Grande do Sul, Porto Alegre, 2016.

SILVA, Carla Maciel; BAPTISTA, Claudio Roberto. Patologização e medicalização da vida: a infância e os processos de escolarização. In: CECCIM, Ricardo Burg; FREITAS Cláudia Rodrigues de. Fármacos, remédios, medicamentos: o que a educação tem com isso? 1. ed. Porto Alegre: Rede Unida, p. 53-64, 2021.

STELMACHUK, Anaí Cristina da Luz; HAYASHI, María Cristina Piumbato. Análise bibliométrica sobre avaliação de pessoas com deficiência intelectual para ingresso em serviços de educação especial. Revista Iberoamericana sobre Calidad, Eficacia y Cambio en Educación, v. 13, n. 2, p. 27-49, 2014. Disponível em: https://revistas.uam.es/reice/article/ view/2789/3004. Acesso em: 07 jun. 2021.

TEZZARI, Mauren Lúcia. Educação especial e ação docente: da medicina à educação. 2009. 240 f. Tese (Doutorado em Educação) - Programa de Pós-Graduação em Educação, Faculdade de Educação, Universidade Federal do Rio Grande do Sul, Porto Alegre, 2009.

WORLD HEALTH ORGANIZATION (WHO). Atlas: Global Resources for Persons with Intelectual Disabilities. Montreal: WHO, 2007.

Data de submissão: 10/05/2021

Data de aceite: 19/06/2021 